\title{
Audiologic Pattern in Elderly Patients: A Tertiary Care Experience
}

\author{
Mohammad Adeel $^{1 *}$ and Muhammad Sohail Awan ${ }^{2}$ \\ ${ }^{1}$ Senior Instructor, Section of Head and Neck oncology, Department of Surgical oncology, Shaukat Khanum Memorial \\ Cancer Hospital, Lahore, Pakistan \\ ${ }^{2}$ Associate Professor, Section of Otolaryngology and Head and Neck Surgery, Department of Surgery, Aga Khan \\ Hospital, Karachi, Pakistan
}

Received: April 24, 2017; Accepted: May 09, 2017; Published: May 29, 2017

*Corresponding author: Dr. Mohammad Adeel, Senior Instructor, Section of Head and Neck oncology, Department of Surgical oncology, Shaukat Khanum Memorial Cancer Hospital, Lahore, Pakistan, Tel: +923335230990; Email: doc.adeel.khan@gmail.com

\begin{abstract}
Background: Like many other countries, the elderly population is on rise in Pakistan. Increasing age has an impact on hearing. Patterns of hearing loss in patients presenting to our clinic was never studied before hence, we decided to analyze the audiological profile of elderly patients undergoing audiometry in our clinic and to see genders differences if there are any.
\end{abstract}

Materials and Methods: It was a Cross-sectional study conducted at Aga Khan Hospital, from January to May 2013. Data was collected regarding audiological complaint, type, degree of hearing loss and hearing thresholds by chart review of 246 patients above age 60 who underwent audiometry at our clinic from Jan to May 2013. The results were statistically analyzed by using t-test for continuous variables and Chi-Square and Fischer exact where appropriate for categorical variables.

Results: In audiologic complaints (hearing loss, tinnitus, Vertigo) We noted a statistically significant difference $(\mathrm{p}<0.01)$ between the genders; tonal audiometry showed a non-significant difference $(p=.307)$. Among men and women, the most common type of hearing loss was sensorineural. No statistical difference $(p=.527)$ was noted in prevalence of presbycusis among gender.

Conclusion: We found a high prevalence of sensorineural hearing loss in both genders. We had a variable degree of hearing loss ranging from mild to profound. The highest prevalence was seen to be that of moderate hearing loss. Comparison of higher frequencies with lower ones on audiometry amongst both gender showed a higher involvement of higher frequencies that gives rise to descending audiometric curves suggestive of presbycusis.

Keywords: Sensorineural hearing loss; Audiometry; Presbycusis

\section{Introduction}

Like any other country, elderly population is also on rise in Pakistan [1]. In 2008, a report published from Pakistan showed that that there were 7.34 million elderly people population in our country was 7.34 million in 1998 and is expected to rise up to 22.07 million in 2030 [1].

Considering the political, social, and economic disturbance; our country i.e. Pakistan has done well in achieving an improved life span. And this fact is evident by its rising elderly population. In 1998, World Health Organization (WHO) published a report stating that approximately $6 \%$ of our population was comprised of people above age of 60 years and it is expected to double by 2025. Life expectancy has been reported to have mounted by approximately 3 decades in the last 50 years and is expected to climb to 72 years by 2023 [2].

Currently at our hospital, one out of every five inpatients is over 65 years of age [3]. Which might not be very appealing as compared to other countries but for a developing country like ours, where financial constraint and lack of funds required to deal with socially and medically susceptible populations present a huge challenge [3].

When we talk about Geriatric medical care, it differs from routine medical care as the primary aim in aforementioned care are conservation of function and improving the quality of life instead of treating and curing certain diseases [4]. Aging is accompanied with increasing incapacity and functional losses such as decreased vision, hearing disability and loss of mobility. The peak onset of incapacity occurs in the age group of 60 years and above. Visual disability is at its peak in this age group followed by hearing disability which leads to high functional disability [5]. Sensorial limitation attributing to impairment of hearing is undoubtedly one of the most appalling reason of isolation of elderly population in the society

Hearing loss could be secondary to multiple etiologies. In majority of cases it has been associated with birth, acquired systemic diseases, ototoxic drugs or aging. Hearing loss can occur at any age, which can have grave implications on social life. Hearing disability in children can have developmental problems, while elderly population have natural hearing loss secondary to aging, known as presbycusis [6].

WHO in 2005 reported that nearly 278 million people had moderate to profound hearing disability while approximately $1 / 4$ th of the elderly people had hearing problems, one-third had significant hearing disability on audiometry [7]. In literature, 
it has been reported that use of hearing aid among hearing impaired elderly results in better levels of social, emotional and cognitive functioning in contrast to the group in which no hearing aid is used to augment hearing [8].

Presbycusis is a process that is associated with aging and is a result of cochlear degeneration, that mainly influences base of cochlea hence impairing hearing acuity in the high frequencies with increasing age [9]. By definition, Presbycusis is abilateral symmetric sensorineural hearing loss (SNHL), that ranges from mild to profound mainly in the high frequencies as well as the low frequencies, having a steady and progressive inception with and without low speech recognition [10].

The elderly's hearing assessment should include a detailed history and examination to ascertain his/ her hearing thresholds. Thus, important factors such as understanding and accomplishment of commands given to the patient must be carried out to get precise results on the handy use of hearing and understanding. This is important because the linguistic inferences are proportionally linked to the degree of hearing loss, which differ between mild to severe hearing loss [11].

Now that it has been well known that the elderly Pakistani population in recent years has been growing faster than the other age ranges, it is worthwhile to better study this population especially in terms of hearing impairment in order to provide them with better quality of life.

The aims of this study were to look for the audiological complaints from a sample of the Pakistani elderly population, characterize their audiometric profile and asses the differences amongst male and female genders.

\section{Material and methods}

We conducted a cross-sectional study in a tertiary care hospital otolaryngology clinic from January to May 2013. Sample size was calculated using WHO sample size determinant software. Keeping in mind prevalence of decreased hearing to be $20 \%$, with bond of error 5\% and confidence interval of 95\%, total of 246 individuals were included in study [12].

All the cases with one or more audiological complaints [hearing loss, tinnitus (noise and ringing sensation in ear), ear fullness, dizziness (a sensation of whirling and loss of balance)] with a minimum age of 60 years who underwent audiometry were included in our study and all those who either had history of exposure to ototoxic medications or noise exposure were excluded from study. All the excluded individuals were replaced by those who fulfilled inclusion criterion. So, we had to review 252 cases to attain our sample size of 246 .

All the individuals were subjected to detailed history, examination including otoscopy and tuning fork tests. Audiometry was performed to look for both air and bone conduction thresholds. We defined types of hearing loss according to criterion defined by Santos \& Rus $\urcorner$ so, in to: normal, conductive, sensorineural and mixed [13]. Degree of hearing loss according to the threshold was classified according to a criterion described by
WHO: <25dBHL normal; 26-40dBHL mild; 41-60 dBHL moderate; 61-80dBHL severe; 81+dBHL profound [14]

Frequencies were further classified in to two groups using a criterion defined by Momensohn-Santosetal: the frequencies of 500, 1000 and $2000 \mathrm{~Hz}$ were classified as low frequencies; and 4000 and $8000 \mathrm{~Hz}$ were grouped in to high frequencies [15]. The degree and types of hearing loss were then analyzed from the mean values of each one of them.

We used SPSS 20 for analysis of data. Results were compared between male and female patients using independent sample $\mathrm{T}$ test for quantitative variables and for the qualitative variables Chi-Square or Fisher's exact test was used where appropriate. P-value of $<0.05$ was considered significant.

\section{Results}

The review in terms of age and gender yielded nonhomogeneous groups in which no statistically significant difference $(p=.634)$ was seen [Table 1].

Table 1: Distribution of the elderly individuals $(n=246)$, according to age in years, comorbids and gender

\begin{tabular}{|c|c|c|c|c|}
\hline Gender & $\mathbf{n}$ & $\begin{array}{l}\text { Mean } \\
\text { Age(years) }\end{array}$ & SD & $\mathbf{P}$ \\
\hline Male & 185 (75.2\%) & 70.37 & 7.89 & \multirow[b]{2}{*}{$.634^{\prime}$} \\
\hline Female & $61(24.7 \%)$ & 69.79 & 9.24 & \\
\hline \multicolumn{5}{|c|}{ Comorbids } \\
\hline & Hypertension & Diabetes & \multicolumn{2}{|c|}{$\begin{array}{l}\text { Chronic renal } \\
\text { failure }\end{array}$} \\
\hline Male & $110(59.4 \%)$ & $52(28.1 \%)$ & \multicolumn{2}{|c|}{$2(1.1 \%)$} \\
\hline Female & $31(50.8 \%)$ & $21(34.4 \%)$ & \multicolumn{2}{|c|}{$1(1.63 \%)$} \\
\hline $\mathrm{P}$ & 0.543 & 0.611 & \multicolumn{2}{|c|}{0.384} \\
\hline
\end{tabular}

$\mathrm{N}$ : number of individuals; SD: standard deviation; $\mathrm{p}$ : $\mathrm{p}$-value *evaluation by the Independent sample T test.

Review of comorbids of the individuals in our study showed that hypertension was the most common comorbid in both gender followed by diabetes. None of the comorbids showed statistical significance [Table 1].

Among the investigated presenting complaints, hearing loss was the most common complaint among males, however, tinnitus was seen more frequently among females [Table 2]. The results were found to be statistically significant $(\mathrm{p}<.001)$.

Otoscopic examination revealed that most common finding in both gender was a normal tympanic membrane and a tympanic membrane perforation was seen only in $9.7 \%$ (18) of males and $14.7 \%$ (9) of females but gender comparison of these findings were not found to have any significance $(\mathrm{p}=.276)$ 
Table 2: Elderly distribution $(n=246)$ according to the presence of audiological or labyrinthine complaints, otoscopic findings and gender

\begin{tabular}{|c|c|c|c|c|c|c|}
\hline \multirow[b]{2}{*}{ Complaints } & \multirow[t]{2}{*}{ Sex } & & & & & \multirow[t]{2}{*}{ P value } \\
\hline & & Hearing loss & Tinnitus & Vertigo & More than 1 & \\
\hline & M & $72(38.9 \%)$ & $33(17.8 \%)$ & $13(7.02 \%)$ & $67(36.2 \%)$ & \multirow{2}{*}{$<.001^{*}$} \\
\hline & $\mathrm{F}$ & $18(29.5 \%)$ & $26(42.6 \%)$ & $1(1.6 \%)$ & $16(26.2 \%)$ & \\
\hline \multirow[t]{3}{*}{ Tympanic membrane } & & \multicolumn{2}{|c|}{ Normal } & \multicolumn{2}{|c|}{ Perforation } & \\
\hline & M & \multicolumn{2}{|c|}{$167(90.2 \%)$} & \multicolumn{2}{|c|}{$18(9.7 \%)$} & \multirow{2}{*}{$.276^{* *}$} \\
\hline & $\mathrm{F}$ & \multicolumn{2}{|c|}{$52(85.2 \%)$} & \multicolumn{2}{|c|}{$9(14.7 \%)$} & \\
\hline \multicolumn{7}{|l|}{ *Fischer exact test } \\
\hline \multicolumn{7}{|l|}{$* *$ chi square } \\
\hline
\end{tabular}

As far as tonal audiometry is concerned, we noted that SNHL was most common type of hearing loss in both gender [Graph I,II] and significant difference was seen among gender only in right ear. In majority of audiograms symmetry was seen in both gender [Graph III] but there was no statistical significance $(\mathrm{p}=.307)$ seen among gender.

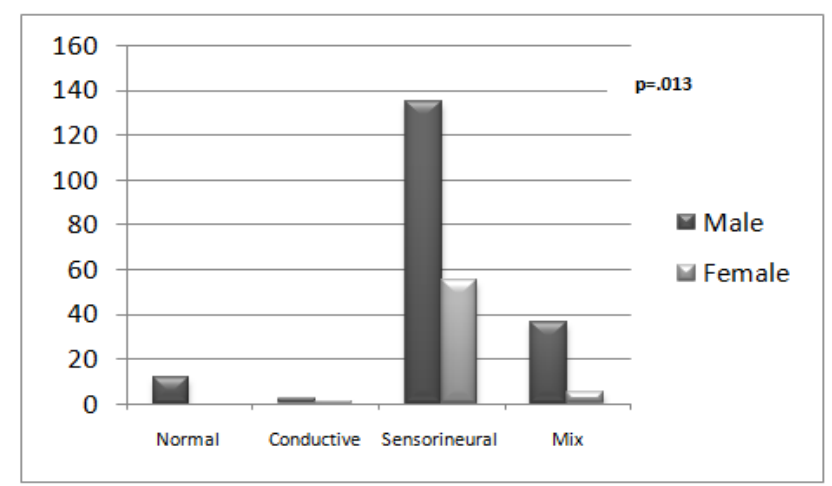

Graph I: Type of hearing loss in the right ear tonal audiometry and gender

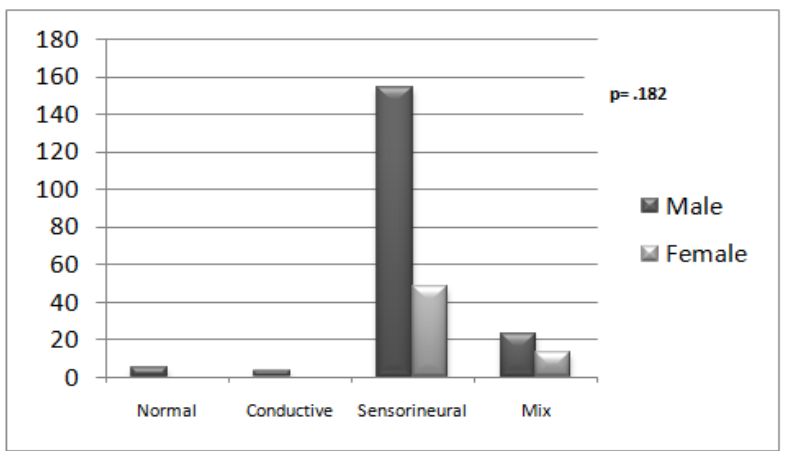

Graph II: Type of hearing loss in the left ear tonal audiometry and gender

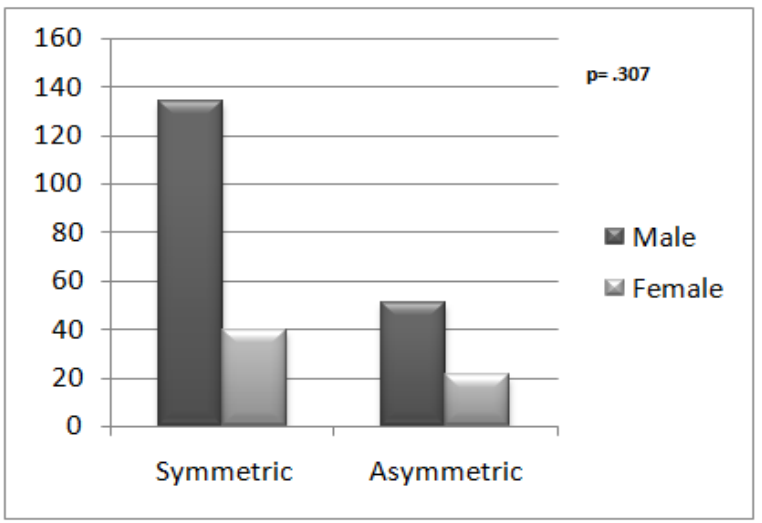

Graph III: Ear symmetry on tonal audiometry and gender

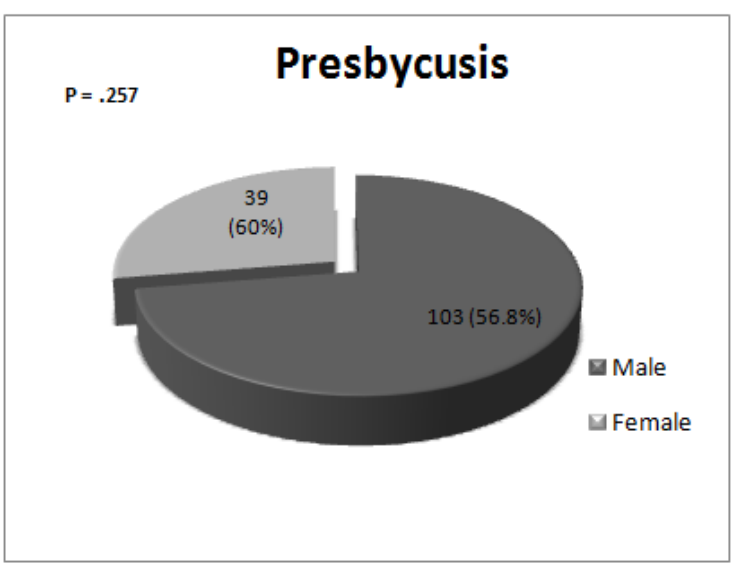

Pie I: Prevalance of presbycusis and gender

Bilateral symmetric SNHL (presbycusis) was seen in more than half of males and females [pie chart I]. It was also not associated with any significance among gender ( $\mathrm{p}=.257)$.

Degree of hearing loss according to WHO criterion as mentioned above revealed a statistically significant difference among both gender especially in higher frequencies [Table 3]. 
Table 3: Degree of hearing loss according to WHO grades of hearing impairment

\begin{tabular}{|c|c|c|c|c|c|c|c|c|c|c|c|c|c|}
\hline \multirow{2}{*}{$\begin{array}{l}\text { Hearing } \\
\text { loss } \\
\text { degree }\end{array}$} & \multicolumn{6}{|c|}{ Low frequencies } & \multirow[t]{2}{*}{$\mathbf{P}$} & \multicolumn{5}{|c|}{ High frequencies } & \multirow[t]{2}{*}{$\mathbf{P}$} \\
\hline & Sex & Normal & Mild & Moderate & Severe & Profound & & Normal & Mild & Moderate & Severe & Profound & \\
\hline \multirow[t]{2}{*}{$\begin{array}{l}\text { Right } \\
\text { ear }\end{array}$} & $\mathrm{M}$ & $\begin{array}{l}54 \\
(29.2 \%)\end{array}$ & $\begin{array}{l}22 \\
(11.9 \%)\end{array}$ & $\begin{array}{l}45 \\
(24.3 \%)\end{array}$ & $\begin{array}{l}25 \\
(13.5 \%)\end{array}$ & $\begin{array}{l}39 \\
(21.1 \%)\end{array}$ & \multirow[t]{2}{*}{$.136^{*}$} & 0 & $\begin{array}{l}35 \\
(18.9 \%)\end{array}$ & $\begin{array}{l}35 \\
(18.9 \%)\end{array}$ & $\begin{array}{l}48 \\
(25.9 \%)\end{array}$ & $\begin{array}{l}67 \\
(36.2 \%)\end{array}$ & \multirow[t]{2}{*}{$.025^{*}$} \\
\hline & $\mathrm{F}$ & $\begin{array}{l}22 \\
(36.1 \%)\end{array}$ & $\begin{array}{l}8 \\
(13.1 \%)\end{array}$ & $\begin{array}{l}13 \\
(21.3 \%)\end{array}$ & $\begin{array}{l}13 \\
(21.3 \%)\end{array}$ & $\begin{array}{l}5 \\
(8.2 \%)\end{array}$ & & 0 & $\begin{array}{l}7 \\
(11.5 \%)\end{array}$ & $\begin{array}{l}23 \\
(37.7 \%)\end{array}$ & $\begin{array}{l}13 \\
(21.3 \%)\end{array}$ & $\begin{array}{l}18 \\
(29.5 \%)\end{array}$ & \\
\hline \multirow[t]{2}{*}{ Left ear } & M & $\begin{array}{l}62 \\
(33.5 \%)\end{array}$ & $\begin{array}{l}23 \\
(12.4 \%)\end{array}$ & $\begin{array}{l}43 \\
(23.4 \%)\end{array}$ & $\begin{array}{l}52 \\
(28.1 \%)\end{array}$ & $\begin{array}{l}5 \\
(2.7 \%)\end{array}$ & \multirow[t]{2}{*}{$<.0001^{* *}$} & 0 & $\begin{array}{l}13 \\
(7.02 \%)\end{array}$ & $\begin{array}{l}44 \\
(23.7 \%)\end{array}$ & $\begin{array}{l}49 \\
(26.5 \%)\end{array}$ & $\begin{array}{l}79 \\
(42.7 \%)\end{array}$ & \multirow[t]{2}{*}{$<.001^{* *}$} \\
\hline & $\mathrm{F}$ & $\begin{array}{l}22 \\
(36.1 \%)\end{array}$ & $\begin{array}{l}21 \\
(34.4 \%)\end{array}$ & $\begin{array}{l}5 \\
(8.2 \%)\end{array}$ & $\begin{array}{l}8 \\
(13.1 \%)\end{array}$ & $\begin{array}{l}5 \\
(8.2 \%)\end{array}$ & & 0 & $\begin{array}{l}6 \\
(9.8 \%)\end{array}$ & $\begin{array}{l}29 \\
(47.5 \%)\end{array}$ & $\begin{array}{l}13 \\
(21.3 \%)\end{array}$ & $\begin{array}{l}13 \\
(21.3 \%)\end{array}$ & \\
\hline
\end{tabular}

Table 4: Hearing threshold in both ear at low and high frequencies in both gender

\begin{tabular}{|c|c|c|c|c|c|c|}
\hline \multirow[t]{2}{*}{ Sex } & \multirow{2}{*}{$\begin{array}{l}\text { Hearing } \\
\text { threshold } \\
\text { (dB) }\end{array}$} & \multicolumn{3}{|c|}{$\begin{array}{l}\text { Low frequencies } \\
\text { (HZ) }(+/-S D)\end{array}$} & \multicolumn{2}{|c|}{$\begin{array}{l}\text { High frequencies } \\
\text { (HZ) (+/-SD) }\end{array}$} \\
\hline & & 500 & 1000 & 2000 & 4000 & 8000 \\
\hline M & Right ear (db) & $\begin{array}{l}46.2 \\
+/-30.1\end{array}$ & $\begin{array}{l}52.7 \\
+/-32.04\end{array}$ & $\begin{array}{l}51.5 \\
+/-32.5\end{array}$ & $\begin{array}{l}60 \\
+/-31.4\end{array}$ & $\begin{array}{l}84.4 \\
+/-24.1\end{array}$ \\
\hline $\mathrm{F}$ & Right ear (db) & $\begin{array}{l}43.8 \\
+/-25.7\end{array}$ & $\begin{array}{l}47.6 \\
+/-22.4\end{array}$ & $\begin{array}{l}47.8 \\
+/-18.8\end{array}$ & $\begin{array}{l}51.3 \\
+/-16.6\end{array}$ & $\begin{array}{l}77.04 \\
+/-18.5\end{array}$ \\
\hline \multicolumn{2}{|c|}{ P value } & $.582^{*}$ & $.252^{*}$ & $.399^{*}$ & $.039 *$ & $.031^{*}$ \\
\hline M & Left ear $(\mathrm{db})$ & $\begin{array}{l}41.8 \\
+/-24.6\end{array}$ & $\begin{array}{l}47.3 \\
+/-24.5\end{array}$ & $\begin{array}{l}50.7 \\
+/-28.3\end{array}$ & $\begin{array}{l}66.5 \\
+/-24.9\end{array}$ & $\begin{array}{l}85.8 \\
+/-25.2\end{array}$ \\
\hline $\mathrm{F}$ & Left ear $(\mathrm{db})$ & $\begin{array}{l}34.02 \\
+/-17.2\end{array}$ & $\begin{array}{l}38.9 \\
+/-17.9\end{array}$ & $\begin{array}{l}41.06 \\
+/-18.9\end{array}$ & $\begin{array}{l}55.5 \\
+/-14.9\end{array}$ & $\begin{array}{l}70 \\
+/-17.9\end{array}$ \\
\hline \multicolumn{2}{|c|}{ P value } & $.023^{*}$ & $.014^{*}$ & $.013^{*}$ & $<.001^{*}$ & $<.001^{*}$ \\
\hline
\end{tabular}

Review of tonal thresholds in decibel (dB) for both low and high frequency showed that male gender was hearing at a significantly higher threshold than female [Table 4]. However, no significance could be demonstrated among gender at speech frequencies in the right ear. Even though hearing threshold was high for men.

\section{Discussion}

The improvements in quality of life, health conditions and early control of acute and chronic infectious and noninfectious diseases have resulted in the growth of elderly population. However, the effects of the aging process on the sensorial capacities have not changed thus, resulting in rise of diseases which are attributed to aging process itself. Presbycusis is a prime example of this, which is characterized by bilateral, symmetrical progressive SNHL [16].

We noticed hypertension as the most common comorbid (59.4\% (110), Men; 50.8\% (31), Women) which is also a proven worsening factor of hearing and its association with presbycusis has been published in literature by Gates et al [17] and Huang et al [18]. Even though, we have not done univariate analysis, hypertension is one of the factors that needs tight control in order to properly treat elderly patients with auditory problems.

Most common presenting complaint in men was decreased hearing (38.9\%) followed by multiple complaints (36.2\%). Whereas, in females, tinnitus (42.6\%) was the most common complaint followed by decrease hearing (29.5\%). Luís et al reported in their study that was carried out on 320 senior citizens demonstrated an incidence of tinnitus to be $64.4 \%$ in men and $72.5 \%$ in women [19]. Rosenthal reported prevalence of $20 \%$ and $42 \%$ in male and female respectively [20].

In our study, the percentage of SNHL in elderly individuals is comparable to literature. One study showed prevalence of SNHL to be $64.23 \%$ in 260 individuals surveyed [6]. In another study done on 331 individuals above 60 years showed that $81 \%$ had SNHL [21]. A study from brazil, Lousietal reported $86.2 \%$ of SNHL in 320 patients that they evaluated [19]. In the 
current study, we found SNHL in 79.7\% individuals.

As far as, prevalence of hearing loss in elderly patients is concerned, there are reports available in literature quoting hearing loss around 98.24\% [16,22-24]. There are other studies that have reported hearing loss to be $77.1 \%$ and $92.5 \%$ respectively $[19,25]$. In our study, we found that $96.7 \%$ of patients had some sort of hearing loss.

Review of audiogram in study by Tatiana et al has shown that $61.66 \%$ of the participants had presbycusis [22]. In a study from china done on 112 patients has reported prevalence of presbycusis to be $50 \%$. In our study on 246 individuals has shown a prevalence of $58.4 \%$. According to gender distribution $60 \%$ of all females had presbycusis and $56.8 \%$ of males had presbycusis.

We also found in our study that men were hearing at relatively higher threshold as compared to female gender These finding were noted for both ears. These results were in concordance to the outcomes presented by Ciobra et al in their study on 460 subjects [26].

\section{Conclusion}

Based on this study, we conclude a high prevalence of SNHL in both genders. We had a variable degree of hearing loss ranging from mild to profound. The highest prevalence was seen to be that of moderate hearing loss. Comparison of higher frequencies with lower ones on audiometry amongst both gender showed a higher involvement of higher frequencies that gives rise to descending audiometric curves suggestive of presbycusis.

\section{References}

1. Sulaiman N. The situation of elderly population in Pakistan: problems and prospects. PJSE. 2008.

2. Kinsella KG, Velkoff VA. An aging world: 2001: Government Printing Office; 2001.

3. Sabzwari SR, Azhar G. Ageing in Pakistan-A New Challenge. Ageing International. 2011;36(4):423-427.

4. Planning WHOECo, Services OoG. Planning and Organization of Geriatric Services: Report of a WHO Expert Committee: WHO; 1974

5. Adelman AM. Twenty common problems in geriatrics: McGraw-Hill Professional Publishing; 2001.

6. Amaral LCG. Perfil audiológico dos pacientes da terceira idade atendidos no Núcleo de Atenção Médica Integrada da Universidade de Fortaleza; Audiologic profile of the elderley patients atended at Fortaleza universityïs integrated medical attention nucleous. Fono Atual. 2004;7(27):58-64.

7. Organization WH. Deafness and hearing impairment.

8. Patterson C. Prevention of hearing impairment and disability in the elderly. Canadian Task Force on the periodic health examination Canadian guide to clinical preventive health care Ottawa: Health Canada. 1994:954-963.

9. Haddad EGM. A ideologia da velhice; The Aged ideology: Cortez;1986.
10. Corso JF. Presbyacusis, hearing aids and aging. International Journal of Audiology. 1977;16(2):146-63.

11. Veras RP, Mattos LC. Audiologia do envelhecimento: revisão da literatura e perspectivas atuais. Rev Bras Otorrinolaringol. 2007;73(1):128-134.

12. Chaudhuri L. Disability in India: Issues and Concerns. 2006.

13. Santos TMM. A prática da audiologia clínica: Cortez editora; 1988.

14. Mathers C, Smith A, Concha M. Global burden of hearing loss in the year 2000. Global burden of Disease. 2000;18.

15. Momensohn-Santos T, Russo I, Bahilo-Neves C, Botelho D, Martins-Dias F, Rodrigues F, editors. Estudo comparativo dos critérios utilizados na classificação do grau da perda auditiva. IX Congresso Brasileiro de Fonoaudiologia;2001.

16.Vitale RF, Ribeiro FAQ. O papel do fator de necrose tumoral alfa (TNF- $\alpha$ ) no processo de erosão óssea presente no colesteatoma adquirido da orelha média. Revista Brasileira de Otorrinolaringologia. 2007;73(1):123-127.

17. Gates GA, Cooper Jr J, Kannel WB, Miller NJ. Hearing in the elderly: the Framingham cohort, 1983-1985. Part I. Basic audiometric test results. Ear Hear. 1990;11(4):247-256.

18. Huang W, Xu J, Gao B, Zhou J, Liu G. Study on the causes and risk factors on vertigo and balance disorders in 118 elderly patients]. Zhonghua liu xing bing xue za zhi. 2005;26(9):720-722.

19. Do Carmo LC, Médicis SJA, Marone S, D’Ottaviano FG, Zagati LL, Dias SLEM. Audiological study of an elderly Brazilian population. Braz J Otorhinolaryngol. 2008;74(3):342-349.

20. Rosenhall U, Karlsson AK. Tinnitus in old age. Scandinavian Audiology. 1991;20(3):165-171.

21. Jurca APK, Pinheiro F, Martins K, Herrera L, Colleone L, Saes S. Estudo do perfil audiológico de pacientes com idade acima de 60 anos. Salusvita. 2002;21(1):51-65.

22. Guerra TM, Estevanovic LP, Cavalcante MÁM, Silva RCL, Miranda ICC, Quintas VG. Profile of audiometric thresholds and tympanometric curve of elderly patients. Braz J Otorhinolaryngol. 2010;76(5):663666.

23. Scheffer JC, Fialho IM, Scholze AS. Itinerários de cura e cuidado de idosos com perda auditiva; Routes of healing and care of elderly individuals with hearing loss. Saúde Soc. 2009;18(3):537-548.

24. Costa K. Estudo de Avaliações Audiológicas de Sujeitos Atendidos numa Clínica Universitária. Fono Atual. 2002;5(20):31-38.

25. Ologe FE, Segun-Busari S, Abdulraheem IS, Afolabi AO. Ear diseases in elderly hospital patients in Nigeria. The J Gerontol A Biol Sci Med Sci. 2005;60(3):404-406.

26. Ciorba A, Benatti A, Bianchini C, Aimoni C, Volpato S, Bovo R, et al. High frequency hearing loss in the elderly: effect of age and noise exposure in an Italian group. J Laryngol Otol. 2011;125(08):776-780. 